\title{
Some Aspects of the Normal Role of Neuromodulators in the Immune System
}

\section{John Smythies}

Center for Brain and Cognition UCSD, The Institute of Neurology University College, London, U.K.

Email: jsmythies@ucsd.edu

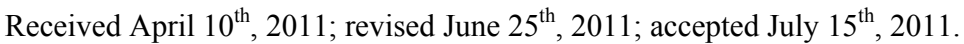

\begin{abstract}
This review covers recent advances in our knowledge of the role of a group of the most prominent neurotransmitters and neuromodulators in the field of the immune reactions of the body. The neurotransmitters and neuromodulators covered are the three catecholamines (epinephrine, noradrenaline and dopamine), serotonin, acetylcholine (both nicotinic and muscarinic functions), and histamine.
\end{abstract}

Keywords: Catecholamines, Acetylcholine, Serotonin, Macrophages, Monocytes

\section{Introduction}

Research over the last few years has revealed the rather unexpected range of the involvement of familiar neurotransmitters and neuromodulators in many cellular functions of the immune system. White blood cells (WBC) both synthesize and export neuromodulators, and bear receptors for neurotransmitters synthesized elsewhere on their plasma membranes. In the nervous system there are two main types of neurotransmission. 1) Those involving specific contacts mediated by boutons termineaux between axons and cell bodies (e.g. as in the glutamate, GABA and acetylcholine systems); and 2) non-specific volume transmission mediated by boutons-en-passage, that activate any of their specific receptors in the vicinity (e.g. as in the catecholamine and serotonin systems). In the immune system there are an instances of direct contacts between sympathetic and parasympathetic nerve terminals and immune cells. Much evidence from various fields has revealed multiple channels of communication between the brain and the immune system. The centrifugal neural pathway, by which the brain modulates immunity, the noradrenergic sympathetic innervation of the primary and secondary lymphoid organs plays a prominent role. In addition to the presence of beta- and alpha-adrenergic receptors on different types of immunocompetent cells, histological studies have demonstrated direct contact between tyrosine-hydroxylase-positive nerve terminals and lymphocytes in the spleen and thymus [1]. This review will, however, focus on the large system of contacts between freely moving white cells and their target modulators/receptors mediated by volume transmission.

\section{Catecholamines}

Catecholamines (E, NE and DA) are involved in white blood cell (WBC) activity in various ways.

1) WBCs carry on their external membranes CA receptors that respond to ambient levels of catecholamines. For example, anxiety raises blood levels of NE that stimulates reactive oxygen species (ROS) formation in monocytes [2]. This process is mediated by NF-kappaB [3]. A number of dopamine receptors (D 2-5) have been detected on WBC, particularly B cells and NK cells (high), neutrophils and eosinophils (moderate), and T-lymphocytes (low) [4]. Macrophages have both alpha 2 and beta 2-adrenergic receptors that exert a mutually antagonistic cross-feedback function on $\mathrm{H}_{2} \mathrm{O}_{2}$ and superoxide release [5]. Lymphocytes carry beta-2 adrenergic receptors [6]. Eosinophils carry beta-adrenergic receptors coupled to adenylate cyclase [7]. Lymphocytes have alpha and beta adrenergic receptors that modulate tritiated thymidine uptake [8].

2) Catecholamines (E), have been detected inside leukocytes, (T-cells, monocytes). The synthesis of catecholamines is promoted inside phorbol activated $\mathrm{T}$ - and B-lymphocytes (but not, the authors claim, macrophages) by means of protein kinase C-dependent induction of tyrosine hydroxylase. This process was inhibited by coincubation with DA (but not E or NE) acting on DA1 [9]. Brown et al. [10] studied catecholamine synthesis and 
release in the RAW264.7 macrophage cell line. Although catecholamines were low in unstimulated cells, they found activation with lipopolysaccharide-induced tyrosine hydroxylase (TH) mRNA and increased extracellular norepinephrine and intracellular dopamine within 48 hours. The catecholamine synthesis inhibitor alpha-methyl-paratyrosine decreased extracellular norepinephrine levels, suggesting release and rapid turnover of newly synthesized norepinephrine. Cosentino et al. [11] report detecting catecholamines in various WBC including lymphocytes, monocytes and granulocytes. Levels were reduced by inhibiting tyrosine hydroxylase and by reserpine. Inhibition of intracellular CA production in human PBMC promotes cell survival through reduction of activationinduced apoptosis, and dopaminergic modulation of TH expression [12]. Both thymic lymphoid and non-lymphoid cells, including epithelial cells and macrophages, have been demonstrated to express tyrosine hydroxylase (TH), and form a local non-neural catecholaminergic cell network involved in the fine tuning of T-cell development [13].

3) Epinephrine interestingly attenuates the binding of certain leucocytes to a marginal pool constituted by the endothelial membrane, thus increasing blood levels of the cytotoxic leukocyte as a rapid response to invading pathogens [14].

4) Miscellaneous functions

Dopamine stimulates expression of the human immunodeficiency virus type 1 via NF-kappaB in peripheral blood mononuclear cells (PBMC) [15]. 1999). Grisanti et al [16] report a unique synergistic pro-inflammatory response mediated through a beta(1)-AR cAMP-dependent mechanism in lipopolysaccharide (LPS)-challenged monocytic cells. Beta2-adrenoceptor stimulation inhibits advanced glycation end products-induced adhesion molecule expression and cytokine production in human PBMC [17]. Norepinephrine inhibits energy metabolism (oxygen consumption) of human peripheral blood mononuclear cells via adrenergic receptors [18]. Catecholamines induce interleukin-10 (IL-10) release in patients suffering from acute myocardial infarction by transactivating its promoter (cAMP, PKA dependent) in monocytes, but not in T-cells ([19]. Beta-adrenergic agonists induce a shift in the human type-1/type-2 cytokine balance toward a type-2 response [20]. Acute sympathetic activation by adrenaline infusion, short-term exercise, or psychological stress also causes a selective increase in circulating CD56+ or CD57+ lymphocytes, which are rich in betaadrenergic receptors. The results of several studies suggest that adrenaline-induced changes in beta-adrenergic receptors and the redistribution of leukocyte subsets may be linked. Beta-adrenergic receptors may mediate immuno-modulatory effects by causing selective cell mobi- lization [21].

Lymphocytes have dopamine D2 ad D4 receptors [22] and can synthesize catecholamines (E, NE and DA) and their synthesis levels may increase in the activated state, and endogenous catecholamines synthesized by the lymphocytes can regulate the function of the lymphocytes themselves [23]. Peripheral human T lymphocytes contain and are able to synthesize CA from normal precursors in physiologic concentrations [24].

\section{Serotonin}

Macrophages have serotonin receptors [25] and lymphocytes have 5HT1A receptors [26]. Eosinophils have serotonin $2 \mathrm{~A}$ receptors involved in chemoattraction [27]. Macrophages possess a specific, active, 5HT uptake system and rapidly metabolize 5HT to its 5-hydroxyindole acetic acid metabolite [28]. Recent advances have implicated serotonin in the immune system as a regulator of inflammation, proliferation, regeneration, repair, and tumor biology. Mossner and Lesch [29] review four major functions for 5-HT on the immune system. These include $\mathrm{T}$ cell and natural killer cell activation, delayed-type hypersensitivity responses, production of chemotactic factors, and natural immunity delivered by macrophages. In the presence of low concentrations of interferon-gamma (IFN-gamma), 5-HT augments phagocytosis, whereas at high concentrations of IFN-gamma, 5-HT suppresses phagocytosis. There is functional evidence that at least part of the modulation of IFN-gamma-induced phagocytosis by 5-HT occurs through a 5-HT receptor-mediated mechanism, and 5-HT, dopamine, and histamine modulate IFN-gamma-induced phagocytosis independently through their respective receptors [30]. Serotonin activates murine alveolar macrophages through 5-HT2C receptors and calcium release [31]. Orally administered tryptophan enhances the phagocytic response and detoxification of superoxide anion radicals derived from this immune function in the peritoneal macrophages of rats, very probably through its conversion to the immunoregulatory molecules, serotonin and melatonin [32].

Peritoneal macrophages express the serotonin transporter [33]. Serotonin can upregulate the activity of peritoneal macrophages through 5-HT(1A) receptors [34]. Serotonin does not enhance tumor cell proliferation, but acts as a regulator of angiogenesis by reducing the expression of matrix metalloproteinase 12 (MMP-12) in tumor-infiltrating macrophages, entailing lower levels of angiostatin - an endogenous inhibitor of angiogenesis. Accordingly, serotonin deficiency causes slower growth of colon tumors by reducing vascularity, thus increasing hypoxia and spontaneous necrosis [35]. In alveolar macrophages serotonin significantly inhibits the production of tumor necrosis factor (TNF) and interleukin (IL)-12, 
whereas IL-10, NO and PGE(2) production are increased. These results suggest that serotonin alters the cytokine network in the lung through the production of prostaglandin E (2) (PGE(2)) [36]. Intracellular 5-HT is necessary for optimal synthesis of IL-6 and TNFalpha; 5HT in physiological concentrations may increase IL-6 and TNFalpha production by stimulating 5-HT(2) receptors; and extracellular 5-HT concentrations above the baseline physiological levels may suppress the production of the above cytokines [37].

Agents postulated to act via phospholipase C, e.g. serotonin, augment the production of hydrogen peroxide. Agents known to increase the intracellular levels of cyclic AMP, e.g. adrenalin and PGE2, reduce the hydrogen peroxide production. Insulin, which is known to decrease cyclic AMP levels, produces opposite results [38]. Serotonin is important for optimal T-cell activation and in macrophage accessory function for T-cell activation [39]. Extensive recent reviews of the highly complex and extensive role serotonin in T-cell activation and function have been published by Ahern [40] and by Pacheco, Riquielme and Kalergis [41].

\section{Acetylcholine (Nicotinic)}

Wessler et al. [42] have presented a review of the extensive phylogenetic range of acetylcholine (ACh) in biological tissues. ACh has been detected in bacteria, algae, protozoa, tubellariae and primitive plants, suggesting an extremely early appearance of ACh in the evolutionary process. In humans, ACh and/or the synthesizing enzyme, choline acetyltransferase, has been demonstrated in epithelial cells (airways, alimentary tract, urogenital tract, epidermis), mesothelial (pleura, pericardium) and endothelial and muscle cells. In addition, immune cells express the non-neuronal cholinergic system.

Several nicotinic cholinergic receptor subtypes have been characterized in B and T lymphocytes, monocytes, macrophages, and dendritic cells [43]. Acetylcholine is predominantly pro-inflammatory for lymphocytes and epithelial cells, anti-inflammatory for mast cells and macrophages, both pro- and anti-inflammatory for monocytes, and variable in neutrophils and eosinophils [44]. Cholinergic mechanisms also play an important role in inflammation through endogenous acetylcholine.

Nicotine activates cholinergic anti-inflammatory pathways. New concepts of reciprocal interactions between nicotine and serotonin are emerging. Inflammatory molecules produced by damaged tissues activate afferent signals through ascending vagus nerve fibers, which act as the sensory arm of an "inflammatory reflex". The subsequent activation of vagal efferent fibers, which represent the motor arm of the inflammatory reflex, rapidly leads to acetylcholine release in organs of the reticuloendothe- lial system, including the spleen, liver, and gastrointestinal tract. Here acetylcholine interacts with $\alpha 7$ subunitcontaining nicotinic receptors in tissue macrophages and other immune cells, which inhibits NF-kappaB nuclear translocation and rapidly inhibits the synthesis/release of tumor necrosis factor- $\alpha$ and other inflammatory cytokines by monocytes and macrophages [45-48]. Monocytes have alpha7 nicotinic acetylcholine receptors that inhibit the production of proinflamatory cytokines by suppression of IkB phosphorylation and nuclear factor-kB transcriptional activity [49]. The cholinergic anti-inflammatory pathway, which acts through the macrophage $\alpha 7$-nicotinic acetylcholine receptor $(\alpha 7 \mathrm{nAChR})$, is important in innate immunity, in obesity-induced inflammation and insulin resistance [50]. Up-regulation of IL-10 production by auto/paracrine $\mathrm{ACh}$ is mediated predominantly through alpha7 $\mathrm{nAChR}$ [51]. Monocytes have nicotinic ACh receptors that are involved in the synthesis of $\mathrm{C} 2$, the second component of complement [52]. Eosinophils have anti-inflammatory alpha-3, -4 and -7 nicotinic ACh receptors that down regulate eosinophil activity [53].

Stimulating the 5-HT(4)R accelerates acetylcholine $(\mathrm{ACh})$ release from cholinergic myenteric neurons, which subsequently activates $\alpha 7 \mathrm{nAChR}$ on activated monocytes/macrophages to inhibit their inflammatory reactions in the muscle layer [54]. In contrast, the $\mathrm{nAChR} \alpha 1$ receptor is an important regulator of calpain-1 activation and inflammation in a new proinflammatory pathway [55]. Rat alveolar monocytes are equipped with modulatory $\mathrm{nACh}$ receptors with properties distinct from the ionotropic $\mathrm{nACh}$ receptors that mediate synaptic transmission in the nervous system. Their stimulation with nicotine dampens ATP-induced $\mathrm{Ca}^{2+}$-release from intracellular stores [56].

\section{Acetylcholine (Muscarinic)}

Granulocytes and monocytes have stereospecific muscarinic ACh receptors [57]. Neutrophils have muscarinic ACh receptors involved in airway function [58]. Eosinophils have muscarinic receptors that modulate intestinal inflammation [59].

Macrophages, expressing functional muscarinic acetylcholine receptors, are able to proliferate in vitro in response to the muscarinic agonist carbachol. These peritoneal cells can use two distinct signaling pathways: 1) by activating arginase producing high levels of prostaglandin $\mathrm{E}(2)$ via $\mathrm{M}(1)-\mathrm{M}(3)$ receptors activation; and 2) by triggering protein kinase $\mathrm{C}$ activity and inducing moderate prostaglandin $\mathrm{E}(2)$ liberation via $\mathrm{M}(1)$ receptor activation [60].

Viral infections increase acetylcholine release and potentiate vagally-mediated bronchoconstriction by blocking inhibitory $\mathrm{M}(2)$ muscarinic receptors on parasympa- 
thetic neurons. TNF- $\alpha$ is a key mediator of THIS virusinduced $\mathrm{M}(2)$ muscarinic receptor dysfunction and airway hyperresponsiveness [61].

\section{Histamine}

The role of histamine-containing basophils in immune reactions (previously somewhat neglected) has been extensively reviewed by Schneider, Wedner, De Moraes and Dy [62]. They summarise their main findings as follows. These cells modulate TH responses through their capacity to generate large amounts of cytokines with proTH2 functions (IL-4, IL-13 TSLP, IL-25). They also contribute to immunoglobulin synthesis and class switching, angiogenesis, autoimmunity, tumor immunity and hematopoiesis by producing cytokines such as IL-6, VEGF, GM-CSF and IL-3.

\section{Microglia}

Microglial cells are the immune-competent elements of the brain. They not only express receptors for chemokines and cytokines, but also for neurotransmitters such as GABA, glutamate, adrenaline ad dopamine [63]. Dopamine receptors trigger the inhibition of the constitutive potassium inward rectifier and activate potassium outward currents in a subpopulation of microglia. Chronic dopamine receptor stimulation enhances migratory activity and attenuates the lipopolysaccharide (LPS)-induced nitric oxide (NO) release as does stimulation of adrenergic receptors. While, however, noradrenaline attenuates the LPS-induced release of TNF-alpha and IL-6, dopamine is ineffective in modulating this response. Catecholamines (E, NE and DA) have been shown to block nitric oxide production by microglia [64].

\section{Conclusions}

It is of interest that the conservative forces of evolution have utilized many of the same molecules for information transfer and control in the nervous and in the immune systems, and have imbued the reactions in which they are engaged with ever increasing complexity, speed and efficiency.

\section{REFERENCES}

[1] T. Hori, T. Katafuchi, S. Take, N. Shimizu and A. Nijima. "The Autonomic Nervous System as a Communication Channel between the Brain and the Immune System," Neuroimmunomodulation, Vol. 2, No. 4, 1995, pp. 203215.

[2] K. Yasunari, T. Matsui, K. Maeda, M. Nakamura, T. Watanabe and N. Kiriike, "Anxiety-Induced Plasma Norepinephrine Augmentation Increases Reactive Oxygen Species Formation by Monocytes in Essential Hypertension," American Journal of Hypertension, Vol. 19, No. 6, 2006, pp. 573-578. doi:10.1016/j.amjhyper.2005.10.027

[3] A. Bierhaus, J. Wolf, M. Andrasy, P. M. Rohleder, P. M. Humpert. D. Petrov, R. Fersti, M. von Eynatten, T. Wendt, G. Rudofsky, M. Joswig, M. Morcos, M. Schwaniger, B. McEwan, C. Kirschbaum and P. P. Nawroth, "A Mechanism Converting Psychosocial Stress into Mononuclear Cell Activation," Proceedings of the National Academy of Sciences of the United States of America, Vol. 100, No. 4, 2003, pp. 1920-1925 doi:10.1073/pnas.0438019100

[4] F. McKenna, P. J. McLaughlin, B. J. Lewis, G. C. Sibbring, J. A. Cummerson, D. Bowen-Jones and R. J. Moots, "Dopamine Receptor Expression on Human T- and B-lymphocytes, Monocytes, Neutrophils, Eosinophils and NK Cells: A Flow Cytometric Study," Journal of Immunology, Vol. 132, No. 1, 2002, pp. 34-40. doi:10.1016/0192-0561(94)90045-0

[5] H. M. Shen, L. X. Sha, J. L. Kennedy and D. W. Ou, "Adrenergic Receptors Regulate Macrophage Secretion," International Journal of Immunopharmacology, Vol. 16, No. 11, 1994, pp. 905-910.

[6] M. M. Khan, P. Sansoni, E. D. Silverman, E. G. Engleman and K. L. Melmon, "Beta-Adrenergic Receptors on Human Suppressor, Helper, and Cytolytic Lymphocytes," Biochemical Pharmacology, Vol. 35, No. 7, 1986, pp. 1137-1142. doi:10.1016/0006-2952(86)90150-4

[7] T. Yukawa, D. Ukena, C. Kroegel, P. Chanez, G. Dent, K. F. Chung and P. J. Barnes. "Beta 2-Adrenergic Receptors on Eosinophils. Binding and Functional Studies," American Review of Respiratory Diseases, Vol. 141, No. 6, 1990, pp. 1446-1452.

[8] J. W. Hadden, E. M. Hadden and E. Middelton Jr, "Lymphocyte Blast Transformation. I. Demonstration of Adrenergic Receptors in Human Peripheral Lymphocytes," Cell Immunology, Vol. 1, No. 6, 1970, pp. 583595. doi:10.1016/0008-8749(70)90024-9

[9] E. Pállinger and G. Csaba, "Presence and Distribution of Biogenic Amines (Histamine, Serotonin and Epinephrine) in Immunophenotyped Human Immune Cells," Inflammation Research, Vol. 57, No. 11, 2008, pp. 530-534.

[10] S. W. Brown, R. T. Meyers, K. M. Brennan, J. M. Rumble, N. Narasimhachari, E. F. Perozzi, J. J. Ryan, J. K. Stewart and K. Fischer-Stenger, "Catecholamines in a Macrophage Line," Journal of Immunology, Vol. 135, No. 1-2, 2003, pp. 47-55.

[11] M. Cosentino, R. Bombelli, M. Ferrari, F. Marino, E. Rasini, G. J. Naestroni, A. Conti, M. Boveri, S. Lecchini and G. Frigo, "HPLC-ED Measurement of Endogenous Catecholamines in Human Immune Cells and Hematopoietic Cell Lines," Life Sciences, Vol. 68, No. 3, 2000, pp. 283-295. doi:10.1016/S0024-3205(00)00937-1

[12] M. Ferrari, M. Cosentino, F. Marino, R. Bombelli, S. Lecchini and G. Frigo, "Dopaminergic D1-Like ReceptorDependent Inhibition of Tyrosine Hydroxylase mRNA Expression and Catecholamine Production in Human Lymphocytes," Biochemical Phamacology, Vol. 67, No. 5, 2004, pp. 865-873.

[13] G. Leposavic, I . Pilipovic, K. Radojevic, V. Pesic, M. 
Perisic and D. Kosec, "Catecholamines as Immunomodulators: A Role for Adrenoceptor-Mediated Mechanisms in Fine Tuning of T-Cell Development," Autonomic Neuroscience, Vol. 144, No. 1, 2008, pp. 1-12. doi:10.1016/i.autneu.2008.09.003

[14] S. Dimitrov, T. Lange and J. Born, "Selective Mobilization of Cytotoxic Leukocytes by Epinephrine," Journal of Immunology, Vol. 184, No. 1, 2010, pp. 503-511. doi:10.4049/jimmunol.0902189

[15] O. Rohr, B. E. Sawaya, D. Lecestre, D. Aunis and E. Schaeffer, "Dopamine Stimulates Expression of the Human Immunodeficiency Virus Type 1 via NF-kappaB in Cells Of The Immune System," Nucleic Acids Research, Vol. 27, No. 16, 1999, pp. 3291-3299. doi:10.1093/nar/27.16.3291

[16] L. A. Grisanti, J. Evanson, E. Marchus, H. Jorissen, A. P. Woster, W. DeKrey, E. R. Sauter, C. K. Combs and J. E. Porter, "Pro-Inflammatory Responses in Human Monocytes Are Beta1-Adrenergic Receptor Subtype Dependent," Molecular Immunology, Vol. 47, No. 6, 2010, pp. 1244-1254.doi:10.1016/j.molimm.2009.12.013

[17] J. D. Lünemann, F. Buttgereit, R. Tripmacher, C. G. Baerwald, G. R. Burmester and A. Krause, "Norepinephrine Inhibits Energy Metabolism of Human Peripheral Blood Mononuclear Cells via Adrenergic Receptors," Bioscience Reports, Vol. 21, No. 5, 2002, pp. 627-635.

[18] H. K. Takahashi, S. Mori, K. Liu, H. Wake, J. Zhang, R. Liu, T. Yoshino and M. Nishibori, "Beta2-Adrenoceptor Stimulation Inhibits Advanced Glycation End ProductsInduced Adhesion Molecule Expression and Cytokine Production in Human Peripheral Blood Mononuclear Cells," European Journal of Pharmacology, Vol. 627, No. 1-3, 2010, pp. 313-317.doi:10.1016/j.ejphar.2009.10.034

[19] U. Riese, S. Brenner, W. D. Döcke, S. Prösch, P. Reinke, M. Oppert, H. D. Volk and C. Platzer, "Catecholamines Induce IL-10 Release in Patients Suffering from Acute Myocardial Infarction by Transactivating Its Promoter In Monocytic but Not in T-Cells," Molecular and Cellular Biochemistry, Vol. 212, No. 1, 2000, pp. 45-50. doi:10.1023/A:1007196602659

[20] S. K. Agarwal and G. D. Marshall Jr, "Beta-Adrenergic Modulation of Human Type-1/Type-2 Cytokine Balance," Journal of Allergy and Clinical Immunology, Vol. 105, No. 1, 2000, pp. 91-98. doi:10.1016/S0091-6749(00)90183-0

[21] R. Landmann. "Beta-Adrenergic Receptors in Human Leukocyte Subpopulations," European Journal of Clinical Investigation, Vol. 22, Suppl. 1, 1992, pp. 30-36.

[22] L. Santambrogio, M. Liparti, A. Bruni and R. Dal Toso, "Dopamine Receptors on Human T- and B-Lymphocytes," Journal of Neuroimmunology, Vol. 45, No. 1-2, 1993, pp. 113-119. doi:10.1016/0165-5728(93)90170-4

[23] Y. H. Qiu, Y. P. Peng, J. M. Jiang and J. J. Wang, "Expression of Tyrosine Hydroxylase in Lymphocytes and Effect of Endogenous Catecholamines on Lymphocyte Function," Neuroimmunomodulation, Vol. 11, No. 1, 2004, pp. 75-83.
[24] N. R. Musso, S. Brenci, M. Setti, F. Indiveri and G. Lotti. "Catecholamine Content and in Vitro Catecholamine Synthesis in Peripheral Human Lymphocytes," Journal of Clinical Endocrinology and Metabolism, Vol. 81, 1996, pp. 3553-3557. doi:10.1210/jc.81.10.3553

[25] E. J. Essman. "Serotonin Receptors on Pulmonary Alveolar Macrophages," Ric Clinic Laboratories, Vol. 15, No. 1, 1985. pp. 19-24.

[26] O. Fajardo, J. Galeno, M. Urbina, I. Carreira and L. Lima, "Serotonin, Serotonin 5-HT(1A) Receptors And Dopamine in Blood Peripheral Lymphocytes of Major Depression Patients," International Immunopharmacology, Vol. 3, No. 9, 2003, pp. 1345-1352. doi:10.1016/S1567-5769(03)00116-4

[27] S. A. Boehme, F. M. Lio, L. Sikora, T. S. Pamdit, K. Lavrador, S. P. Rao and P. Sriramarao, "Cutting Edge: Serotonin Is a Chemotactic Factor for Eosinophils and Functions Additively with Eotaxin," Journal of Immunology, Vol. 173, No. 6, 2004, pp. 3599-3603.

[28] R. Mössner and K. P. Lesch, "Role of Serotonin in the Immune System and in Neuroimmune Interactions," Brain Behavior and Immunity, Vol. 12, No. 4, 1998, pp. 249-271.

[29] J. C. Jackson, R. F. Walker, W. H. Brooks and T. L. Roszman, "Specific Uptake of Serotonin by Murine Macrophages," Life Sciences, Vol. 42, No. 17, 1988, pp. 203-215. doi:10.1016/0024-3205(88)90443-2

[30] E. M. Sternberg, H. J. Wedner, M. K. Leung and C. W. Parker, M. Rosas-Ballina and K. J. Tracey, "Effect of Serotonin (5-HT) and Other Monoamines on Murine Macrophages: Modulation of the Interferon-Gamma Induced Phagocytosis," Journal of Immunology, Vol. 138, No. 12,1987, pp. 4360-4365.

[31] Z. Mikulski, Z. Zaslona. L. Cakarova, P. Hartmann, J. Wilhelm, L. H. Tecott, J. Lohmayer and W. Kummer, "Serotonin Activates Murine Alveolar Macrophages through 5-HT2C Receptors," American Journal of Physiology Lung Cellular and Molecular Physiology, Vol. 299, No. 2, pp. 272-280.

[32] S. Sanchez, S. D. Paredes, C. L. Sanchez, C. Barriga, R. J. Reiter and A. B. Rodruigez, "Tryptophan Administration in Rats Enhances Phagocytic Function and Reduces Oxidative Metabolism," Neuroendocrinology Letters, Vol. 29, No. 6, 2008, pp. 1026-1032.

[33] M. L. Rudd, A. N. Nicolas, B. L. Brown, K. FischerStenger and J. K. Stewart, "Peritoneal Macrophages Express the Serotonin Transporter," Neuroimmunology, Vol. 159, No. 1-2, 2005, pp. 113-118.

[34] M. Freire-Garabal, M. J. Núñez, J. Balboa, P. LópezDelgado, R. Gallego, T. García-Caballero, M. D. Fernández-Roel, J. Brenlla and M. Rey-Méndez, "Serotonin Upregulates the Activity of Phagocytosis through 5-Ht1a Receptors," British Journal of Pharmacology, Vol. 139, No. 2, 2003, pp. 457-463. doi:10.1038/sj.bjp.0705188

[35] A. Nocito, F. Dahm, W. Jochum, J. H. Jang, P. Georgiev, M. Bader, R. Graf and P. A. Clavien, "Serotonin Regulates Macrophage-Mediated Angiogenesis in a Mouse 
Model of Colon Cancer Allografts," Cancer Research, Vol. 68, No. 13, 1998, pp. 5152-5158.

[36] G. Ménard, V. Turmel and E. Y. Bissonnette, "Serotonin Modulates the Cytokine Network in the Lung: Involvement of Prostaglandin E2," Clinical and Experimental Immunology, Vol. 150, No. 2, 2007, pp. 340-348.

[37] M. Kubera, M. Maes, G. Kenis, Y. K. Kim and W. Lason, "Effects of Serotonin and Serotonergic Agonists and Antagonists on the Production of Tumor Necrosis Factor Alpha and Interleukin-6," Psychiatry Research, Vol. 134, No. 3, 2005. pp. 251-258. doi:10.1016/j.psychres.2004.01.014

[38] D. J. Kodomerkos, S. A. Kalamidas and O. B. Kotoulas, "In Vitro Effects of Hormones and Autacoids on the Hydrogen Peroxide Production and the Morphology of Endotoxin-Activated Rat Peritoneal Macrophages," Histology and Histopathology, Vol, 18, No. 1, 1988, pp. 203215.

[39] M. R. Young and J. P. Matthews, "Serotonin Regulation of T-Cell Subpopulations and of Macrophage Accessory Function," Immunology, Vol. 84, No. 1, 1995, pp. 148152.

[40] G. P. Ahern. "5-HT and the Immune System," Current Opinion in Pharmacology, 8 March 2011, Epub ahead of print.

[41] R. Pacheco, E. Riquelme and M. Kalergis, "Emerging Evidence for the Role of Neurotransmitters in the Modulation of T Cell Responses to Cognate Ligands," Central Nervous System Agents in Medicinal Chemistry, Vol. 10, No. 1, 2010, pp. 65-83.

[42] I. Wessler, C. J Kirkpatrick and K. Racké, "The Cholinergic 'Pitfall': Acetylcholine, a Universal Cell Molecule in Biological Systems, Including Humans," Clinical and Experimental Pharmacology and Physiology, Vol. 26, No. 3, 1999, pp. 198-205.

doi:10.1046/j.1440-1681.1999.03016.x

[43] I. Cloëz-Tayarani and J. P. Changeux. "Nicotine and Serotonin in Immune Regulation and Inflammatory Processes: A Perspective," Journal of Leukocyte Biology, Vol. 81, No. 3, 2007, pp. 599-606.

[44] C. R. Gwilt, L. E. Donnelly and D. F. Rogers, "The NonNeuronal Cholinergic System in the Airways: An Unappreciated Regulatory Role in Pulmonary Inflammation?" Pharmacology and Therapeutics, Vol. 115, No. 2, 2007, pp. 208-222.doi:10.1016/j.pharmthera.2007.05.007

[45] S. L. Oke and K. J. Tracey, "From CNI-1493 to the Immunological Homunculus: Physiology of the Inflammatory Reflex," Journal of Leukocyte Biology, Vol. 83, No. 3, 2008, pp. 512-517.doi:10.1189/jlb.0607363

[46] M. Rosas-Ballina and K. J. Tracey, "The Neurology of the Immune System: Neural Reflexes Regulate Immunity," Neuron, Vol. 64, No, 1, 2009, pp. 28-32.

[47] D. Giuliani, A. Ottani, D. Altavilla, C. Bazzani, F. Squadrito and S. Guarini, "Melanocortins and the Cholinergic Anti-Inflammatory Pathway," Advances in Experimental and Medical Biology, Vol. 681, 2010, pp. 7187. doi:10.1007/978-1-4419-6354-3 6
[48] H. Wang, M. Yu, M. Ochani, C. A. Amelia, M. Tanovic, S. Susaria, J. H. Li, H. Wang, H. Yang, L. Ulloa, Y. Al-Abed, C. J. Czura, and K. J. Tracey, "Nicotinic Acetylcholine Receptor Alpha7 Subunit Is an Essential Regulator of Inflammation," Nature, Vol. 421, No. 6921, pp. 384-388

[49] H. Yoshikawa, M. Kurakowa, N. Ozaki, K. Nara, K. Atou, E. Takada, H. Kamochi and N. Sazuki, "Nicotine Inhibits the Production of Proinflammatory Mediators in Human Monocytes by Suppression of I-kappaB Phosphorylation and Nuclear Factor-kappaB Transcriptional Activity through Nicotinic Acetylcholine Receptor Alpha7," Clinical and Experimental Immunology, Vol. 146, No. 1. 2006, pp. 116-123.

[50] X. Wang, Z. Yang, B. Xue and H. Shi, "Activation of the Cholinergic Antiinflammatory Pathway Ameliorates Obesity-Induced Inflammation and Insulin Resistance," Endocrinology, Vol. 152, No. 3, 2011, pp. 836-846.

[51] A. I. Chernavasky, J. Arredondo, M. Skok and S. A. Grando, "Auto/Paracrine Controlof Inflammatory Cytokines by Acetylcholine in Macrophage-Like U937 Cells Through Nicotinic Receptors," International Immunopharmacology, Vol. 10, No. 3, 2010, pp. 308-315. doi.org/10.1016/j.intimp.2009.12.001

[52] K. Whaley, D. Lappin and T. Barkas, "C2 Synthesis by Human Monocytes Is Modulated by a Nicotinic Cholinergic Receptor," Nature, Vol. 293, No. 5833, 1981, pp. 580-583.

[53] M. R. Blanchet, A. Langlois, E. Israël-Assayag, M. J. Beaulieu, C. Ferland, M. Laviolette and Y. Cormier. "Modulation of Eosinophil Activation in Vitro by a Nicotinic Receptor Agonist," Journal of Leukocyte Biology, Vol. 81, No. 5, 2007, pp. 1245-1251, Epub 2007 Feb 8. doi.org/10.1189/jlb.0906548

[54] Y. Tsuchida, F. Hatao, M. Fujisawa, T. Murata, M. Kaminishi, Y. Seto, M. Hori and H. Ozaki, "Neuronal Stimulation with 5-Hydroxytryptamine 4 Receptor Induces Anti-Inflammatory Actions via \{Alpha\}7nACh Receptors on Muscularis Macrophages Associated with Postoperative Ileus," Gut, Vol. 60, No.5, 2011, pp. 638647.

[55] G. Zhang, A. L. Thomas, A. L. Marshall, K. A. Kernan, Y. Su, Y. Zheng, J. Takano, T. C. Saido and A. A. Eddy, "Nicotinic Acetylcholine Receptor $\alpha 1$ Promotes Calpain-1 Activation and Macrophage Inflammation in Hypercholesterolemic Nephropathy," Laboratory Investigations, Vol. 91, No.1, 2011, pp. 106-123.

[56] Z. Mikulski, P. Hartmann, G. Jositsch, Z. Zastona, K. S. Lips. U. Pfeil, H. Kurzen, J. Lohmeyer, W. G. Clauss, V. Grau, M. Fronius and W. Kummer, "Nicotinic Receptors on Rat Alveolar Macrophages Dampen ATP-Induced Increase in Cytosolic Calcium Concentration," Respiration Research, Vol. 11, No. 1, 2010, pp. 133-156. doi:10.1186/1465-9921-11-133

[57] A. Lopker, L. G. Abood, W. Hoss and F. J. Lionetti, "Stereoselective Muscarinic Acetylcholine and Opiate Receptiors in Human Phagocytic Leukocytes," Biochemical Pharmacology, Vol. 29, No. 10, 1980, pp. 1361- 
1365. doi:10.1016/0006-2952(80)90431-1

[58] R. Gosens, J. Zaagsma, H. Meurs and A. J. Halayko, "Muscarinic Receptor Signaling in the Pathophysiology of Asthma and COPD," Respiratory Research, Vol. 7, No. 1, 2006, pp. 73-79. doi.org/10.1186/1465-9921-7-73

[59] C. Wallon, M. Persborn, M. Jönsson, A. Wang, V. Phan, M. Lampinen, M. Vicario, J. Santos, P. M. Sherman, M. Carlson, A. C. Ericson, D. M. McKay and J. D. Söderholm, "Eosinophils Express Muscarinic Receptors and Corticotropin-Releasing Factor to Disrupt the Mucosal Barrier In Ulcerative Colitis," Gastroenterology, Vol. 140, No. 5, 2011, pp. 1597-1607.

[60] E. de la Torre, A. M. Genaro, M. L. Ribeiro, R. Pagetto and M. E. Sales, "Proliferative Actions of Muscarinic Receptors Expressed in Macrophages Derived from Normal and Tumor Bearing Mice," Biochimica Biophysica Acta, Vol. 1782, No. 2, 2008, pp. 82-89.

[61] Z. Nie, G. D. Scott, P. D. Weiss, A. Itakura, A. D. Fryer and D. B. Jacoby, "Role of TNF- $\alpha$ in Virus-Induced Airway Hyperresponsiveness and Neuronal M(2) Muscarinic Receptor Dysfunction," British Journal of Pharmacology, 1 April 2011, Epub ahead of print. doi:10.1111/j.1476-5381.2011.01393.x.

[62] E. Schneider, N. Thieblemont, M. L. De Moraes and M. Dy, "Basophils: New Players in the Cytokine Network," European Cytokine Network, Vol. 21, No. 3, 2010, pp. 142-153.

[63] K. Färber, U. Pannasch and H. Kettenmann, "Dopamine and Noradrenaline Control Distinct Functions in Rodent Microglial Cells," Molecular and Cellular Neuroscience, Vol. 29, No. 1, 2005, pp. 128-138.

[64] J. Y. Chang and L. Z. Liu. "Catecholamines Inhibit Microglial Nitric Oxide Production," Brain Research Bulletin, Vol. 52, No. 6, 2000, pp. 525-530. doi:10.1016/S0361-9230(00)00291-4 